\title{
The Effect of Speech Rate on Listening Comprehension of EFL learners
}

\author{
Abdolmajid Hayati \\ Shahid Chamran University of Ahvaz, Ahvaz, Iran. \\ Email: majid_hayati@yahoo.com \\ Received August $2^{\text {nd }}, 2010$; revised August 21 ${ }^{\text {st }}, 2010$; accepted August 27 $7^{\text {th }}, 2010$.
}

\begin{abstract}
The present research examined the effect of speech rate on listening comprehension of Iranian EFL learners. Initially, a sample of 108 sophomore EFL learners majoring in English translation was selected based on systematic random sampling from Abadan Islamic Azad University. Then, based on an ECCE proficiency test, 62 participants were chosen and divided into two homogeneous groups of 31. One group had exposure to natural speech rate and the other to slow speech rate of listening materials. After thirteen academic sessions, the results o the paired t-test regarding the pre-tests and post-tests of the two group means showed that both differences (group one: -2.83 and group two: -1.22 ) were significant at 0.05 levels $(\mathrm{P}<0.05)$. These findings suggest that each speech rate, whether natural or slow, could improve EFL learners listening comprehension; however, natural speech rate could demonstrate greater improvements than slow speech rate in EFL learners' listening comprehension.
\end{abstract}

Keywords: Listening Comprehension, Speech Rate, EFL

\section{Preliminaries}

Numerous scholars [1-5] have stated that one of the major aspects of listening comprehension and speaking fluency is speech rate which has also been the focus of recent English as a Foreign / Second Language research. Some researchers [6-9] contend that listening comprehension is affected by many factors like unfamiliar lexis, speech rate, and background knowledge. Learners have been observed to demonstrate a listening problem mainly because of speech rate. Zhao (1997) [5] states that the conflicting findings of the previous studies suggest that the issue with speech rate is far from settled and needs more productive investigation.

Basically, speech rate, as one of the main factors, has caused one of the major difficulties in evaluating listening comprehension. This controversy over what level of speech rate best serves the learners has not yet been resolved. Some methodologists $[10,11]$ believe that speech rate should go up as the students make progress. Their assumption is that listening comprehension and speech rate are inter-related and as speech rate goes up listening comprehension goes down. Others [1-3,12,13] contend that students should be exposed to listening materials with normal speech rate right from the start.
Slow rate of speech is generally believed to be usually easier to comprehend than natural speech rate; this gives the students enough time to process the stream of information at a slower rate of delivery. But does it count for listening comprehension in the long run? In other words, because comprehension is increased in slow speech rate, students should be exposed to slow rate. However; the question that remains to be answered is how students will perform in listening comprehension if exposed to moderate speech rate. Note that there are many factors such as length of passage, syntactic complexity, vocabulary, discourse structure, noise level, accent, register, propositional density, amount of redundancy, socio-cultural knowledge, pragmalinguistic knowledge, contextual knowledge, world knowledge, background knowledge, cognitive and affective factors that affect listening comprehension $[4,14]$. At the same time, speech rate varies from speaker to speaker, age to age, dialect to dialect, context to context, and occasion to occasion. Although speech rate can cover only a small proportion among the above-mentioned variables, it seems to play one of the major controlling roles in listening comprehension that has formed the main initiative for the development of this research. 


\subsection{Statement of the Problem}

One of the major problems most Iranian EFL listeners complain about is speech rate that seems to have exerted an influential effect on their listening comprehension. Speech rate as one of the main variables and factors in listening comprehension has been the main subject of research lately [5,14-16]. For Iranian EFL learners, approaching L2 listening based on spoken, non- reduced input can be overwhelming. Not only must they cope with linguistic input beyond their actual level of proficiency, the time available is also often too short to pay attention to input form [4]. Limitations in L2 learners' working memory and time do not always permit them to process natural listening input (normal speech rate). In non-interactional listening where EFL listeners have no control over the stream of speech rate they are exposed to, it has been observed that listeners are encountered with some listening comprehension problems mostly related to speech rate $[6,8,9]$. But how students will be trained to deal with speech rate in listening comprehension is still a controversial issue that needs more investigation [5].

Most studies conducted on speech rate in foreign contexts deal with appropriate tendencies of speech rate or Word per Minute (WPM) for certain levels, but rarely has any one touched on the issue of how to practice improving our listening comprehension by speech rate. There is also a lack of research on this issue in our context Iran. Therefore, the main objective that has prompted the development of this research is the question of how to overcome the problem of speech rate in listening comprehension by being exposed to natural or slow speech rate.

\subsection{Research Questions}

The main questions to be perused in this study are as follows:

1) If sophomore EFL learners are exposed to natural speech rate for a certain period of time, how well will they perform in listening comprehension?

2) If sophomore EFL learners are exposed to slow (VOA special English) speech rate for a certain period of time, how well will they perform in listening comprehension?

\subsection{Research Hypotheses}

H01: Listening to natural speech rate has no significant effect on sophomore EFL students' listening comprehension.

H02: Listening to slow speech rate has no significant effect on sophomore EFL students' listening comprehension.

\section{Review of Literature}

Zhao (1997) [5] found some valuable results about speech rates. He pointed out that speech rate is something controlled individually rather than by groups. What is new about his study is that past research looked at speech holistically while Zhao viewed it individually. He designed an experiment with four conditions in which participants have control over speech rate in conditions two and three while no control in conditions one and four. Note that not every subject listens to the same passage in conditions 2,3 , and 4 . This was controlled by a computer program. In condition one, the participants listen to 20 sentences while in the other three conditions they listen to passages. Sentences in the first condition were presented at a speed of $180 \mathrm{wpm}$. Conditions 2 and 3 differed in the way that once participants in condition 2 choose their ideal speed rate they cannot change it during listening but in condition 3, the participants had the chance to choose their desired speed rate while listening. In condition 4, the passage is delivered at the speed of $194 \mathrm{wpm}$ and the participants have no control over the speed of the speech. In each condition subjects are asked to complete multiple-choice questions after listening. The participants in Zhao's study were 15 non-native speakers of English from China, Colombia, Venezuela, Turkey, Taiwan, and Korea. His results show that the participants comprehended better when they had control of speech rate. At the end, he concludes that by giving the control of speech rate to the students and by attending to individuals instead of groups, a) when given control, students' listening comprehension improved and b) improved listening comprehension was achieved by slowing down the speech rate.

Cauldwell (1996) [15] introduced some specific software to remedy the problem of comprehending fast speech rate. He states that the capability of his audio-stack software - access, editing, and zooming - made it possible to be more optimistic about the possibility of teaching and learning "fast speech rules" in the classroom or language laboratory. His software, as he points out, can present fast speech in such a way that learners can have direct encounters with the phenomena of normal speech and thus be in a better position to learn both to perceive and comprehend fast speech in the classroom.

Griffiths (1990) [1] studied the effect of speech rate on comprehension of a semi-scientific text that was read aloud at three different speech rate levels and found that moderately fast $(200 \mathrm{wpm})$ speech rates reduced comprehension, but a slow rate of delivery did not increase comprehension significantly as compared to speech delivered at a normal rate. In another descriptive study, Griffiths (1991) [2] stated that language learners are 
likely to meet a far greater speed of rates than the rates investigated in the earlier study. In a similar study but with different materials (stories rather than semi-scientific texts), Griffiths (1992) [3] conducted an experiment on 24 Omani elementary school teachers for a five-week course. He provided three story passages with three different speech rates: slow speech rates $(127$ wpm), average speech rates (188), and fast speech rates. Based on the participants' scores in listening comprehension, he concluded that a slower rate of delivery resulted in better comprehension scores than fast and average rates (although average rates did not lead to better results than fast rates).

Most researchers agree that speech rate has created a problem in listening comprehension and may be a key and controlling factor too. The above studies largely deal with or are generalized around: whether fast speech rate increases or decreases comprehension, if slow speech increases or decreases comprehension, or what speech rate is the ideal one $[1-3,17]$, how to control speech rate, giving control of speech rate to the learners or controlling speech rate by devices $[5,15]$, the effect of native speakers or nonnative speakers' speech rate on listening comprehension [18], or whether speeding up or slowing down of the speech rate correlate with the ease or difficulty level of listening items / tasks [14]. They mostly deal with how learners performed on fast speech rate or slow speech rate and conclusions are mostly contradictory from one researcher to the other $[4,5,14,17]$.

\subsection{The Rationale for the Present Study}

The present study has viewed speech rate from another perspective to provide some novelty. While most researchers test the effect of fast or slow speech rate on listening comprehension, this research tries to give speech rate another perspective and examines learners' performance on two types of natural speech and slow speech rate. In the above research slow speech was mechanically modified by inserting long pauses [17] or prolonging the time to make it slow.

Blau (1999) [17] felt that reduced velocity and inserted pauses, although usually yielding slightly higher comprehension scores, are not a significant aid. However our sample of VOA special English (slow speech rate) did not have these characteristics and slowness did not remove so much of its naturality. There were not long pauses or prolonged sentences but rather the slow speech was presented just as natural as possible word by word. This slow speech rate is not mechanically slowed down by devices, but rather the newscaster reads the news in a slow way word by word or chunk by chunk while the phonetic features and intonation patterns of the speech are preserved and are not broken down. None of the above studies tested the learners' performance on another type of speech rate after exposure to one type of speech (exposure). It means how learners would react to moderate speech rate if they had only exposure to natural speech rate. Or what is the learners' reaction to moderate speech rate after having exposure to slow speech rate after almost three month.

Most of the above literature fails to have an obvious definition of slow or fast speech rate and most researchers do not agree on one definition. One of the main problems they encountered in their research was in operationalizing the speech rate variable. In this context, research has identified the difficulties involved in defining speech rate and especially in deciding what constitutes a 'fast' as opposed to a 'slow' rate [4,5,14]. These difficulties are further compounded by the fact that speech rates may vary throughout a text. An average wpm count will not reflect these differences and therefore cannot provide any information that will help the researcher to understand the effect of speech rate at the level of the individual item. The moderate version that is used for pretest and posttest is neither slow nor a fast speech rate. But rather a version of speech rate designed for testing listening comprehension for pedagogical purpose. Therefore, it is not a natural speech rate as defined earlier. Because of the difficulty existing in defining fast, moderate, or slow speech rate in the field of speech rate and listening comprehension research, moderate speech rate has been labeled by the researcher's to be neither slow as VOA nor natural speech rate, but something in between them depicting his own perception.

\section{Methodology}

\subsection{Participants}

In the present research, the participants were chosen from BA students of Islamic Azad University of Abadan. They were studying English translation in their fourth semester. The population was 108 male and female students. The 62 homogeneous participants drawn from this sample were randomly divided into two experimental groups of 31 . There were 27 females and 4 males in group one who had exposure to natural speech rate; and there were 26 females and 5 males in group two who had exposure to slow speech rate. In group one, the average age was 25.29 ranging from 19 to 46 . There were 17 bilinguals with Arabic-Persian backgrounds, 1 TurkishPersian bilingual, 3 Kurdish-Persian bilingual, and the rest were Persian monolinguals. In Group two, the average age was 24.61 ranging from 19 to 39 . There were 12 
bilinguals with Arabic-Persian backgrounds, 1 KurdishPersian bilingual, and the rest were Persian monolinguals. Note that learners' bilingualism, age, and gender were not considered as variables and are presented here only to describe the participants.

\subsection{Instrumentation}

A proficiency Michigan Examination for the Certificate of Competency in English (ECCE) [19], multiple-choice test of 60 items was first administered to 10 fourth semester EFL subjects from Islamic Azad University of Abadan and after an interval of two weeks the same test was administered to the same 10 subjects and the reliability of the test and the retest was calculated as $r=0.83$. When the reliability was assured, this test was administered to 108 EFL populations in order to select the homogeneous subjects. The other instrument was a 20 -item multiple-choice listening comprehension Examination for the Certificate of Competency in English (ECCE) test that served as pre-test and post-test for both experimental groups. The reliability of the test before administration of the pretest was calculated by the correlation between the means of test and retest by two weeks interval between the test and retest. The reliability coefficients was calculated based on correlation coefficient and it was met as $r$ $=0.87$.

It is worth noting that group one was exposed to natural speech rate such as audio and video news, interviews, political speeches, and lectures; and group two was exposed to slow speech rate materials such as VOA special English news, interviews, political speeches, and lectures. Assignments given to both groups also included out of class activities alongside class activities. Participants were permitted to work in groups to check the video or audio scripts.

\subsection{Procedures}

A 60-item language proficiency test of ECCE Michigan [19] whose reliability coefficient was met, was prepared and administered to $108 \mathrm{EFL}$ subjects. Then, for the purpose of selecting the homogeneous participants, those who scored one standard deviation below and above the mean were called for the next phase of the study. After that, they were randomly divided into two experimental groups of 31 participants. Their classes were held once a week for 90 minutes for thirteen sessions.

Before any treatment, a different listening test of ECCE was administered to measure the participants' listening comprehension; in fact, this listening test of 20 multiple choice items designed for pre-intermediate to intermediate EFL level functioned as both pre-test and post-test for both groups. It is a listening test. In order to make sure of the reliability of the pre-test, it was administered to 10 fourth semester EFL majoring BA translation students twice within two weeks intervals. The reliability of the pre-test obtained by the coefficient correlation between the test and retest was $r=0.87$. After the reliability of the pretest was assured, it was administered to both experimental groups to measure their listening comprehension knowledge.

Based on the video or audio materials, learners sometimes had to listen to a clip of 3-5 minutes listening text to answer some listening comprehension questions. Sometimes they had to transcribe the listening materials. Other activities included video clips with covered subtitle at first and after working out the text, the uncovered subtitle, followed by some listening comprehension questions.

It is important to note that some in-class and outof-class listening activities were worked out in groups. Sometimes assignments included transcription of an audio or video clip of their own materials. However, in order to avoid taboos in video clips, the socio-cultural appropriateness of materials was checked with the subjects before they were brought into the classroom.

\section{Results}

The performance of group one (natural speech rate) on pretest and posttest produced a difference between their scores. Table 1 below shows the participants' performance on the 20 item multiple-choice listening comprehension pre- and posttest.

This was followed by paired $t$-test as depicted in Table 2.

The significance value for the $t$ test indicates that there is a significant difference between the pretest and posttest. The difference was also significant even at 0.001 level. Performance of the participants in group two, who had exposure to VOA slow speech rate, on multiple-choice listening comprehension test also revealed that there existed a difference between the means of pretest and posttest (see Table 3).

Once the raw scores were obtained, paired $t$-test was calculated. Table 4 illustrates the comparison of these two means.

Comparison of the pre-test and post-test means indicated a significant improvement over learners' listening comprehension.

A comparison between means and t-observed of the two groups showed that the mean difference between 
Table 1. Descriptive statistics of group one's pretest and posttest.

\begin{tabular}{cccc}
\hline & $\mathrm{N}$ & Mean & Std. Deviation \\
\hline Group 1 pre-test & 31 & 10.74194 & 3.306234 \\
Group 1 post-test & 31 & 13.58065 & 2.486955 \\
\hline
\end{tabular}

Table 2. Group 1 paired t-test.

\begin{tabular}{|c|c|c|c|c|c|c|c|c|}
\hline & \multicolumn{5}{|c|}{ Paired differences } & \multirow{3}{*}{$\mathrm{t}$} & \multirow{3}{*}{$\mathrm{df}$} & \multirow{3}{*}{$\begin{array}{c}\text { Sig } \\
\text { (2-tailed) }\end{array}$} \\
\hline & \multirow{2}{*}{ mean } & \multirow{2}{*}{ Std. Deviation } & \multirow{2}{*}{ Std. error mean } & \multicolumn{2}{|c|}{$\begin{array}{l}95 \% \text { confidence interval of } \\
\text { the difference }\end{array}$} & & & \\
\hline & & & & Lower & upper & & & \\
\hline pair 1 pre-post test & -2.838710 & 2.517893 & 0.452227 & -3.762280 & -1.915139 & -6.277 & 30 & 0.000 \\
\hline
\end{tabular}

Level of significance $=0.05 \quad \mathrm{Sig}=0.000 \quad t$ observed $=-6.277 \quad \mathrm{t}$ critical $=2.000$

Table 3. Descriptive statistics: pre-test and post-test results of group two.

\begin{tabular}{cccc}
\hline & $\mathrm{N}$ & Mean & Std. Deviation \\
\hline Group2 pre-test & 31 & 11.35484 & 2.763432 \\
Group 2 post-test & 31 & 12.58065 & 2.202638 \\
\hline
\end{tabular}

Table 4. Group 2 paired t-tes.t.

\begin{tabular}{|c|c|c|c|c|c|c|c|c|}
\hline & \multicolumn{5}{|c|}{ Paired differences } & \multirow{3}{*}{$\mathrm{t}$} & \multirow{3}{*}{$\mathrm{df}$} & \multirow{3}{*}{$\begin{array}{c}\text { Sig } \\
(2-\text { tailed })\end{array}$} \\
\hline & \multirow[t]{2}{*}{ mean } & \multirow{2}{*}{$\begin{array}{l}\text { Std. } \\
\text { Deviation }\end{array}$} & \multirow{2}{*}{$\begin{array}{l}\text { Std. error } \\
\text { mean }\end{array}$} & \multicolumn{2}{|c|}{$\begin{array}{l}95 \% \text { confidence interval of the } \\
\text { difference }\end{array}$} & & & \\
\hline & & & & lower & upper & & & \\
\hline Pair 2 pre-post test & -1.22581 & 3.007875 & 0.540230 & -2.32910 & -1.22509 & -2.269 & 30 & 0.031 \\
\hline
\end{tabular}

$t$ observed $=-2.269$ level of significance $=0.031$ at 0.05

Table 5. Paired t-test of G1 \& G2 pre-and posttests.

\begin{tabular}{|c|c|c|c|c|c|c|c|c|}
\hline & \multicolumn{5}{|c|}{ Paired differences } & \multirow{3}{*}{$\mathrm{t}$} & \multirow{3}{*}{ df } & \multirow{3}{*}{$\underset{\text { (2-tailed) }}{\text { Sig }}$} \\
\hline & \multirow{2}{*}{ mean } & \multirow{2}{*}{$\begin{array}{c}\text { Std. } \\
\text { Deviation }\end{array}$} & \multirow{2}{*}{ Std. error mean } & \multicolumn{2}{|c|}{$\begin{array}{l}95 \% \text { confidence interval of } \\
\text { the difference }\end{array}$} & & & \\
\hline & & & & lower & upper & & & \\
\hline Pair 1 pre-post test & -2.83871 & 2.517893 & 0.452227 & -3.76228 & -1.91514 & -6.277 & 30 & 0.000 \\
\hline Pair 2 pre-post test & -1.22581 & 3.007875 & 0.540230 & -2.32910 & -1.22509 & -2.269 & 30 & 0.031 \\
\hline
\end{tabular}

pretest and posttest of group one was higher compared to that of group two. Statistically, differences found in group one are simply more significant than those of group two (See Table 5).

As indicated in Table 5, there is enough significant difference in t-observed and t-critical as well as level of significance of group one to reject $\mathrm{H} 01$ not only at 0.05 level but also at 0.001 level. It is worth mentioning that the level of significance for rejecting the null hypothesis was set at the 0.05 level of significance for both hypotheses (H01 and H02).

\section{Discussion}

In the following, research questions are respectively discussed and answered.

1) If sophomore EFL learners are exposed to natural speech rate for a certain period of time, how well will they perform in listening comprehension?

Table 5 shows that participants' performance on pretest is much different from their performance on posttest. Results suggest that participants' exposure to natural speech rate had a significant effect on the improvement of their listening comprehension. The results related to the first hypothesis are in agreement with Rivers (1981) [11], Chastain (1988) [10], and Brindley and Slayer's (2002) [14] ideas on natural speech. In the same line, Rivers (1981) [11] believes that learners should be exposed to natural speech and when speech is mechanically slowed it is not desirable; and learners can understand natural speech even in the early stages of language learning.

2) If sophomore EFL learners are exposed to slow 
(VOA special English) speech rate for a certain period of time, how well will they perform in listening comprehension?

A comparison between the means of pretest (11.35) and posttest (12.58) of group two showed a difference. Group two performances on listening comprehension posttest showed that although they had only exposure to slow speech rate, their performance had an improvement which was not comparable to that of group one. However, the difference (0.031) was large enough at 0.05 level of significance to reject the null hypothesis. It implies that listening comprehension is affected by fast or slow speech but exposure to slow speech rate is constructive and formative as well. Although the degree of its formativeness and construction is not obviously so clear, it demonstrated a degree of improvement.

There are a lot of intervening factors that might change the results of research or the results one gains might not be because of the treatment. Speech rate in listening comprehension cannot be easily studied if other factors are not taken into account. Speech rate whether slow or fast is strongly affected by other factors such as formality and informality of the speech, the situation type, the relationship between speaker and listener, level of technicality of that speech or its jargon, learners background and world knowledge and many other factors [14]. However, this research could somehow imply that participants' exposure to natural speech rate made a better improvement over those exposed to slow speech rate. What is important to note is that this research can partially imply that in designing any listening material, fastness or slowness of speech rate do make a difference but what makes the biggest difference is the naturalness of both material and speech rate. Slow speech rate or fast speech rate are only a short path practice for comprehending natural speech rate. Therefore, mechanical slowing down and speeding up the speech rate is not a long term objective in teaching and learning listening comprehension.

Now compare slow speech rate with slow motion video. Slow motion in video can give a clearer picture of what eyes may skip or miss in natural motions. Although slow audio may not be well compared with video motion, it can be noticed that video slow motions are usually used only for special purposes by detectives, scientists, sports professionals, etc; on the other hand, slow audio might be used for the same purpose but in EFL / ESL listening comprehension in general and speech rate in particular that may suggest a different sense. As slow motion videos can give a better visual picture, slow audio or slow speech rate can give not only a good phonological fracture of speech rate but also a good practice to listening comprehension.
Researchers have to guard against the idea that comprehending slow speech rate is not an end but rather a short path practice to comprehend natural speech. The reason might be that when speech rate is mechanically slowed down some critical features of naturalness are potentially removed from the speech. EFL / ESL listeners do not usually go around asking their interlocutors to slow down their speech, rather slowing down in speech may happen rarely when the global features of communication are broken down. It means, in real life experience in L1 as well as L2, naturalness is more marked or prominent than unnaturalness. It might also be true about EFL / ESL speech rate in listening comprehension. Students had better practice to deal with natural speech rate, although they might have started with slow speech rate.

Sometimes learners' capability and flexibility in EFL / ESL listening comprehension research is underestimated. As Chastain (1988) [10] has indicated, first language learners can comprehend speech rate even over 400 words per minute and learners' ears can be attuned or accustomed to different speech rates. What is more, the reason we raised the issue of cognition and metacognition in review of literature was that to support the idea that speech rate in listening comprehension is a process happening in the mind of learners and we have no control over that. That means, what is slow to one student might be fast to the other. So these are the students who decide on fastness and slowness of speech rate in listening comprehension and it is a phenomenon controlled individually. Therefore, metacognition is more manifested than cognition or we can observe and, to some extent, have a control over students' metacognitive learning strategy than cognition [20]. The results of Goh's [7,8,21,22] and Vandergrift's [23-25] research on cognition and metacognition in EFL / ESL listening comprehension when accompanied by Zhao's (1997) [5] research on speech rate as an individual factor are somehow the manifestation of the relationship between speech rate and cognition and metacognition in listening comprehension.

Comprehending natural speech is the optimal objective in EFL / ESL listening comprehension; however, problems or obstacles that make this input overwhelming to learners might be related to the limitation of working memory. Jensen and Vinther (2003) [4] state that an utterance should linger in the listener's working memory long enough to be processed, not only for meaning, but also, subsequently, for form. The time constraint on working memory is an obstacle to this process of natural speech rate. They state that natural speech does not give learners enough time to pay attention to the form and meaning of speech, and as a result, noticing hypothesis [4] is not observed. According to the noticing hypothesis, it 
is crucial for the development of learners' interlanguage (IL) to have plenty of opportunity to pay attention to the formal features of the input they receive. Their solution for this shortcoming was to use exact repetition and reduced speech rate. This solution may provide good grounds to advocate slow speech rate in listening comprehension. Some researchers also used some similar approaches to make up for this shortcoming [1-3,14, $17,18]$ and mostly used speech rate reduction. Others $[5,15]$ used devices to slow down speech rate and gave the control of speech rate to the listeners. These alternatives might partially have some potentialities for controlling fast speech rate but the controversy of fast (natural) or slow speech rate is not settled down yet and needs more comprehensive research.

\section{Conclusions and Implications}

The results of the two experiments presented in this research focused on the effect of natural and slow speech rate on Iranian EFL learners' listening comprehension. The assumption to use natural speech rate was motivated by the fact that natural spoken language constitutes a large input in listening comprehension, and on the other hand, there are limitations for learners to comprehend this natural input in EFL / ESL context; therefore, slow speech rate (VOA) has been another compensation for the learners' limitations to be investigated. The results of the two experiments conducted in the present study provided positive answers to our hypotheses and research questions. That is, listening or exposure to natural speech rate made a significant improvement in learners' listening comprehension. This improvement was manifested in their post test compared to their pretest. On the other hand, learners' exposure to slow (VOA) speech rate also demonstrated an improvement. However, the significance of the improvement in exposure to natural speech rate was greater than exposure to slow speech rate. What is clear in this research is that natural and slow speech rates both have some features that can be beneficial to the listeners. That is, it is difficult to include one to the exclusion of the other. But the degree of benefit learners gained in natural speech rate drove us to the point to indicate for now that naturalness counts better for listening comprehension, although slow speech rate suggested an improvement in listeners' comprehension. Although others $[1-3,17]$ might have come to different conclusions on the issue of slow or fast speech rate in listening comprehension, the naturalness of speech counted better in this research.

In teaching and learning listening comprehension, speech rate cannot be overlooked. But the decision to use what materials is vital to the whole concept of teaching and learning listening comprehension. Although the re- sults of this research implied that natural speech rate made improvement in listening comprehension, it does not mean slow speech rate should be excluded. Teachers and learners should take into account features of slow and natural speech rate and know that both have some advantages and disadvantages. But if comprehending natural speech rate is the optimal objective, therefore, the attention and focus should be given to natural speech rate rather than to slow speech rate. Slow speech rate may be used as a short path practice for comprehending natural speech rate.

\section{REFERENCES}

[1] R. Griffiths, "Speech Rate and NNS Comprehension: A Preliminary Study in Time-Benefit Analysis," Language Learning, Vol. 40, No. 3, 1990, pp. 311-336.

[2] R. Griffiths, "Language Classroom Speech Rates: A Descriptive Study," TESOL Quarterly, Vol. 25, No. 1, 1991, pp. 189-194.

[3] R. Griffiths, "Speech Rate and Listening Comprehension: Further Evidence of the Relationship," TESOL Quarterly, Vol. 26, No. 2, 1992, pp. 385-390.

[4] E. D. Jensen and T. Vinther, "Exact Repetition as Input Enhancement in Second Language Acquisition," Language Learning, Vol. 53, No. 3, 2003, pp. 373-428.

[5] Y. Zhao, "The Effects of Listeners' Control of Speech Rate on Second Language Comprehension," Applied Linguistics, Vol. 18, No. 1, 1997, pp. 49-68.

[6] C. S. Chiang and P. Dunkel, "The Effect of Speech Modification, Prior Knowledge, and Listening Proficiency on EFL Lecture Learning," TESOL Quarterly, Vol. 26, No. 2, 1992, pp.345-369.

[7] C. C. M. Goh, "Meta-Cognitive Awareness and Second Language Listeners," English Language Teaching Journal, Vol. 51, No. 4, 1997, pp. 361-369.

[8] C. C. M. Goh, "A Cognitive Perspective on Language Learners' Listening Comprehension Problems," System, Vol. 28, No. 1, 2000, pp. 55-75.

[9] W. S. Wu, "Research and Development of Online Adaptive Placement Test of Listening Comprehension: A Preliminary Report," Journal of Education and Foreign Languages and Literature, Vol. 1, 2005, pp. 147-160.

[10] K. Chastain, "Developing Second Language Skills: Theory and Practice," University of Virginia, Virginia, 1988.

[11] M. W. Rivers, "Teaching Foreign-Language Skills," The University of Chicago Press, Chicago, 1981.

[12] J. Harmer, "The Practice of English Language Teaching," Pearson Education Limited, England, 2001.

[13] J. C. Richards, "Listening Comprehension: Approach, Design, Procedure," TESOL Quarterly, Vol. 17, No. 2, 1983, pp. 219-240.

[14] G. Brindley and H. Slatyer, "Exploring Task Difficulty in ESL Listening Assessment," Language Testing, Vol. 19, 
No.4, 2002, pp. 369-394.

[15] R. M. Cauldwell, "Direct Encounters with Fast Speech on CD-Audio to Teach Listening," System, Vol. 24, No.4, 1996, pp. 521-528.

[16] P. Dunkel, "Listening in the Native and Second / Foreign Language: Toward an Integration of Research and Practice," TESOL Quarterly, Vol. 25, No. 3, 1991, pp. 431457.

[17] E. K. Blau, "The Effect of Syntax, Speed and Pauses on Listening Comprehension," TESOL Quarterly, Vol. 24, No. 4, 1990, pp. 746-753.

[18] J. M. Munro and T. Derwing, "What Speaking Rates Do Non-Native Listeners Prefer?" Applied Linguistics, Vol. 22, No. 3, 2001, pp. 324-337.

[19] J. G. Mennen, "Michigan ECCE Practice Test," Oxford University Press, Oxford, 2005.

[20] A. Wenden, "Metacognition: An Expanded View on the Cognitive Abilities of L2 Learners," Language Learning, Vol. 37, No. 4, 1991, pp. 573-595.
[21] C. C. M. Goh, "How ESL Learners with Different Listening Abilities Use Comprehension Strategies and Tactics," Language Teaching Research, Vol. 2, No. 2, 1998, pp. 124-47.

[22] C. C. M. Goh, "Exploring Listening Comprehension Tactics and Their Interaction Patterns," System, Vol. 30, No. 2, 2002, pp. 185-206.

[23] L. Vandergrift, "Orchestrating Strategy Use: Toward a Model of the Skilled Second Language Listener," Language Learning, Vol. 53, No. 3, 2003, pp. 463-496.

[24] L. Vandergrift, "Relationships among Motivation Orientations, Metacognitive Awareness and Proficiency in L2 Listening," Applied Linguistics, Vol. 26, No. 1, 2005, pp. 70-89.

[25] L. Vandergrift, "Second Language Listening: Listening Ability or LanguageProficiency?" The Modern Language Journal, Vol. 90, No. 1, 2006, pp. 6-19. 